\title{
Efficient large-scale preparation and purification of short single-stranded RNA oligonucleotides
}

\author{
Maria Zlobina, Ondrej Sedo, Ming-Yuan Chou, Lucia Slepankova, and Peter J. Lukavsky \\ Central European Institute of Technology, Masaryk University, Brno, Czech Republic.
}

BioTechniques 60:75-83 (February 2016) doi 10.2144/000114383

Keywords: single-stranded RNA; hammerhead ribozyme; isotope-labelled RNA; structural biology; RNA desalting

Supplementary material for this article is available at www.BioTechniques.com/article/114383.

Sequence-specific RNA recognition by RNA-binding proteins plays a crucial role in the post-translational regulation of gene expression. Biophysical and biochemical studies help to unravel the principles of sequence-specific RNA recognition, but the methods used require large amounts of single-stranded RNA (ssRNA). Here we present a fast and robust method for large-scale preparation and purification of short SSRNA oligonucleotides for biochemical, biophysical, and structural studies. We designed an efficiently folding, self-cleaving hammerhead $(\mathrm{HH})$ ribozyme to prepare ssRNA oligonucleotides. Hammerhead ribozyme RNAs self-cleave with over 95\% efficiency during in vitro transcription as a function of magnesium concentration to produce high yields of the desired ssRNA products. The resulting ssRNAs can be purified from crude transcription reactions by denaturing anion-exchange chromatography and then desalted by weak anion-exchange chromatography using volatile ammonium bicarbonate buffer solutions. The ssRNA oligonucleotides produced this way are homogenous, as judged by mass spectrometry (MS), and are suitable for biochemical and biophysical studies. Moreover, for high-resolution NMR structure determination of RNA-protein complexes, our protocol enables efficient preparation of ssRNA oligonucleotides with various isotope-labeling schemes which are not commercially available.

Unravelling molecular principles of RNA sequence recognition by proteins is necessary for a better understanding of post-transcriptional regulation of gene expression. Regulatory RNA-protein interactions occur during multiple steps of gene expression, such as pre-mRNA processing (1), splicing (2,3), translation (4), RNA transport, localization (5), and degradation (6). Biophysical and biochemical studies aimed at elucidating mechanisms and structural details of RNA-protein interactions in these processes require short singlestranded RNA (ssRNA) oligonucleotides. Custom ssRNA oligonucleotides can be purchased from a range of companies at different yields and quality. This simple solution is appropriate for preliminary studies when small amounts of sSRNA oligonucleotides suffice; however, it does not suit large-scale RNA-protein interaction studies that require large quantities of numerous ssRNA oligonucleotides. Such studies include screening of suitable ssRNA for X-ray crystallography, or NMR spectroscopy of RNA-protein complexes, as well as extensive RNA mutagenesis to deduce or confirm sequence specificity of ssRNA-protein interactions. Furthermore, high-resolution structure determination of ssRNA and ssRNA-protein complexes by NMR spectroscopy requires isotopically-labeled ssRNA oligonucleotides, which are not commercially available. Therefore, there is a demand for a fast and robust protocol for ssRNA oligonucleotide preparation in house that can provide ssRNA oligonucleotides quickly and inexpensively, as well as allow for different labeling patterns. RNA in vitro transcription with T7 RNA polymerase allows the production of milligram quantities of RNA oligonucleotides $(7,8)$, and some methods for in vitro RNA oligonucleotide preparation and purification are currently available (9-15). However, the existing approaches either require the design of an RNA for trans-cleavage (14) or include multiple purification steps that lead to product losses (11). Other drawbacks of existing protocols include the requirements for starting sequence, low yield (13), use of RNase $\mathrm{H}$ in the transcription reaction (15), and lack of robust ssRNA oligonucleotide purification procedures (10). Therefore, none

\section{METHOD SUMMARY}

To produce short single-stranded RNA (ssRNA), we used a 5' cis-acting hammerhead (HH) ribozyme that self-cleaves during T7 in vitro transcription. The ssRNA oligonucleotides were then purified from the transcription reaction under denaturing conditions using high-performance liquid chromatography. Further ssRNA oligonucleotide desalting was performed using fast protein liquid chromatography with volatile buffers. 
A

\begin{tabular}{|c|c|c|c|c|c|c|}
\hline $\begin{array}{c}\text { DNA } \\
\text { template } \\
\text { design }\end{array}$ & $\begin{array}{c}\text { DNA } \\
\text { template } \\
\text { preparation }\end{array}$ & $\begin{array}{c}\text { DNA } \\
\text { template } \\
\text { amplification }\end{array}$ & $\begin{array}{c}\text { RNA trial } \\
\text { transcription }\end{array}$ & $\begin{array}{c}\text { RNA large- } \\
\text { scale } \\
\text { transcription }\end{array}$ & $\begin{array}{c}\text { RNA } \\
\text { purification }\end{array}$ & $\begin{array}{c}\text { RNA } \\
\text { desalting and } \\
\text { concentration }\end{array}$ \\
\hline & $\begin{array}{l}\text { - Primers ordering } \\
\text { (1 day) } \\
\text { - PCR (1.5 hour) } \\
\text { - Ligation and } \\
\text { transformation ( } 1 \text { day) } \\
\text { - Sequencing ( } 1 \text { day) }\end{array}$ & $\begin{array}{l}\text { - Bacteria growth } \\
\text { ( } 2 \text { days) } \\
\cdot \text { Plasmid DNA } \\
\text { purification (6 hours) } \\
\cdot \text { Plasmid linearization } \\
\text { (1 day) }\end{array}$ & & & & $\begin{array}{l}\text { - Buffer exchange } \\
\text { with FPLC system } \\
\text { (1 hour) } \\
\text { - Lyophilization } \\
\text { (1 day) }\end{array}$ \\
\hline 1 hour & 3 days & 3 days & 2.5 hours & 4-24 hours & 1.5 hour & 1 day \\
\hline
\end{tabular}

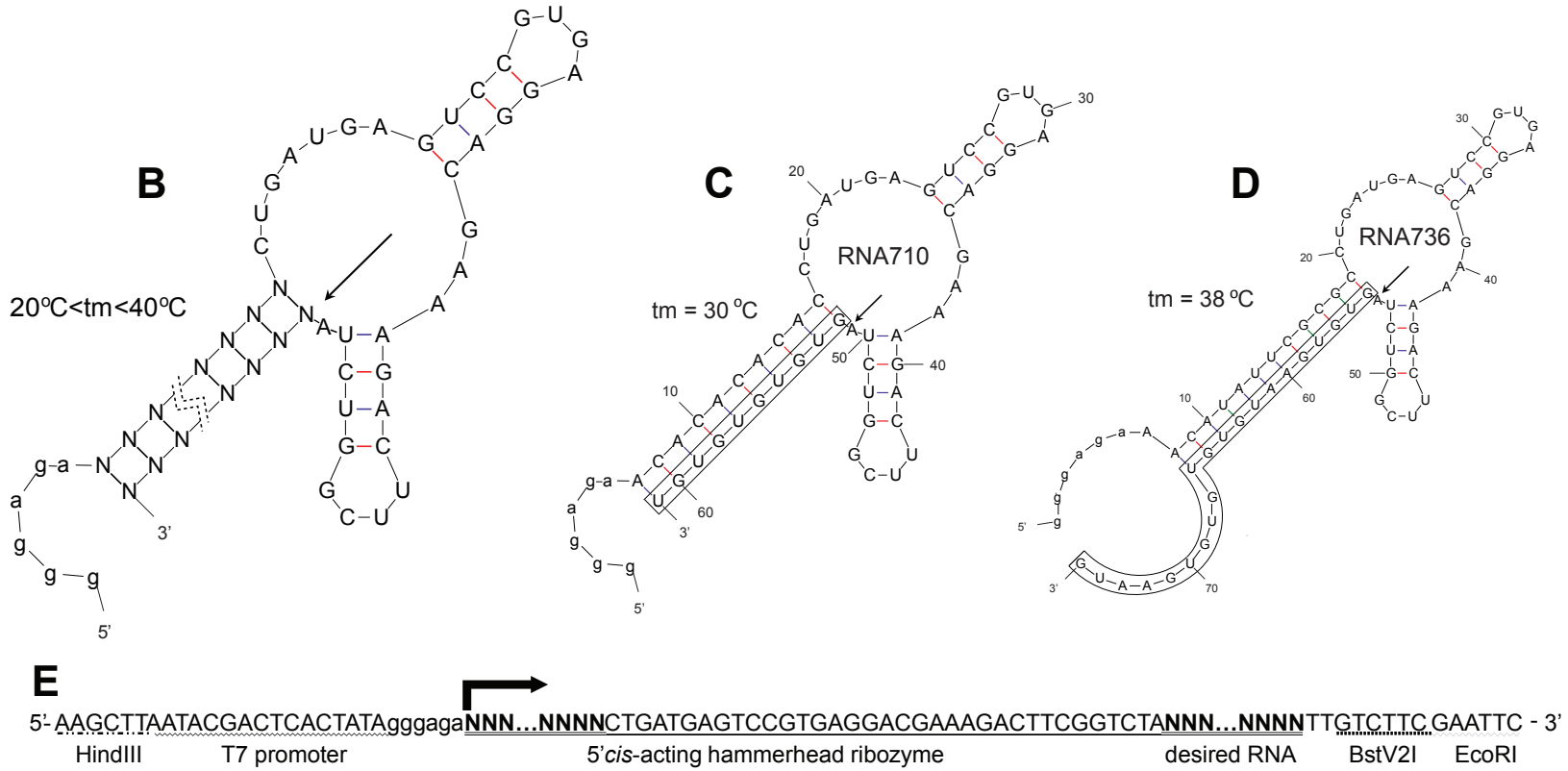

Figure 1. Overview of the single-stranded RNA (ssRNA) oligonucleotide preparation technique. (A) Estimated timeline of the procedure. (B-E) Design of the DNA template. Secondary structures of hammerhead $(\mathrm{HH})$-containing full-length RNA transcript with core ribozyme containing two tetraloops and a variable helix (B). (C,D) Secondary structure of the folded full-length transcript for producing either RNA710 (C) or RNA736 (D) (Table 1). Desired RNA products are enclosed in a black frame, and arrows indicate the $\mathrm{HH}$ cleavage site. The melting temperature for variable helices is shown. Arrow indicates HH self-cleavage site. (E) Sequence of the 5' cis-acting HH DNA template for in vitro transcription inserted into pUC18. The starting sequence of the $\mathrm{HH}$ (indicated with bent arrow) is variable and should be complimentary to the desired RNA sequence to form helixes up to 12 bp.

of the existing methods can provide fast and robust production of pure and short (<20 nucleotides) ssRNA oligonucleotides suitable for biochemical, biophysical, and structural studies.

Here we present a quick and easy protocol routinely used in our laboratory that enables efficient preparation of large amounts of short ssRNA oligonucleotides. The method was tested for ssRNA oligonucleotides ranging from 7 to 21 nucleotides in length, but it can also be applied for shorter and longer ssRNAs if their transcript sequence allows proper hammerhead $(\mathrm{HH})$ ribozyme folding. The whole procedure from plasmid DNA template design to obtaining pure ssRNA takes about 8 days (Figure 1A). Using a 5 ' cis-acting $\mathrm{HH}$ ribozyme and effective purification under denaturing conditions, followed by desalting using weak anionexchange chromatography with volatile buffer solutions, allows production of homogeneous ssRNA oligonucleotides. Our protocol is simple and can be accomplished with standard laboratory equipment and minimal reagent costs. Moreover, this approach is compatible with various isotope-labeling schemes to create labelled ssRNA oligonucleotides needed for NMR structural studies of ssRNA-protein interactions or RNA structure and dynamics $(16,17)$.

\section{Materials and methods}

Preparation of transcription template Double-stranded DNA templates for the ssRNA oligonucleotides were prepared by PCR using the primers listed in
Supplementary Figure S1 and inserted into a pUC18 vector as described previously (18). Plasmids confirmed by sequencing to contain the desired sequence were transformed into $\mathrm{DH} 5 \alpha$ cells. Before the first preparation of large quantities of plasmid DNA, optimal yields should be monitored. The plasmid was purified from harvested cells using the QIAGEN Plasmid Mega Kit (Qiagen, Venlo, Limburg, The Netherlands) following the manufacturer's protocol with some modifications. During cell lysis, buffer volumes were $125 \mathrm{~mL}$ instead of $50 \mathrm{~mL}$ as described for the QIAGEN Plasmid Mega Kit. After protein precipitation and centrifugation, the cell lysate was filtered either with a sterile bottle-top filter (Corning, Corning, NY) or with Miracloth (Millipore, Billerica, 
MA) before loading it onto a QIAGENtip 2500 column. After loading the cell lysate, the QIAGEN-tip 2500 column was washed with 6-8 column volumes (CV) of washing buffer QC. All other steps were performed as described in the manufacturer's protocol. Average plasmid yield was 3-5 mg using the modified protocol as described above. Plasmid DNA was dissolved in Chromasolv water for HPLC (SigmaAldrich, St. Louis, MO) at a concentration of $700 \mu \mathrm{g} / \mathrm{mL}$ and linearized with BstV2I (Sibenzyme, Novosibirsk, Russia) overnight at $37^{\circ} \mathrm{C}$ using 80 units of enzyme per $1 \mathrm{~mL}$ plasmid DNA solution. Linearized plasmid DNA solution was tested for RNase contamination by overnight incubation of 500 ng pure 41 nucleotide ssRNA with $1 \mu \mathrm{L}$ plasmid solution at $37^{\circ} \mathrm{C}$ and subsequent analysis by denaturing PAGE (12\% acrylamide, $8 \mathrm{M}$ urea) visualized with $0.1 \%$ toluidine blue. QIAGEN-tips 2500 from QIAGEN Plasmid Mega Kit were regenerated after DNA elution by a protocol suggested by Siddappa et al. (19). This protocol was adapted for use with QIAGEN-tip 2500 columns. Briefly, columns were stored in $1 \mathrm{M} \mathrm{HCl}$ for $3-5$ days and then rinsed with $5 \mathrm{CV}$ of sterile water and $1 \mathrm{CV}$ of $70 \%$ ethanol, then air-dried and kept dry until the next usage.

RNA in vitro transcription and cleavage All further procedures used Chromasolv water for HPLC and chemicals purchased from Sigma-Aldrich. T7 RNA polymerase and iPP were prepared in-house $(11,20)$.

A
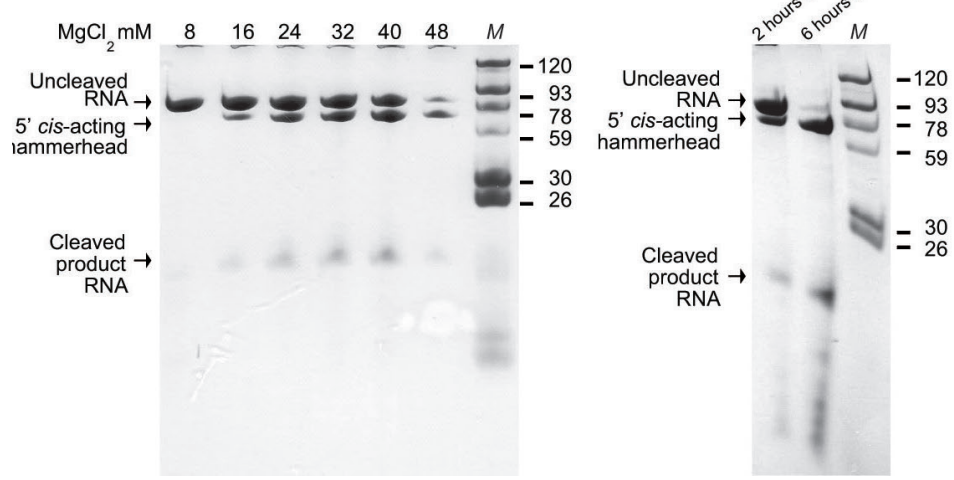

In vitro transcription was optimized for each DNA template in $25 \mu \mathrm{L}$ trial reactions with varying $\mathrm{MgCl}_{2}$ concentrations, from 8 to $48 \mathrm{mM}$ as previously described $(18,21)$ (Figure 2). Large-scale transcription reactions (5-20 mL) typically contained $70 \mu \mathrm{g} /$ $\mathrm{mL}$ linearized plasmid DNA template, $4 \mathrm{mM}$ each rNTP, $1200 \mathrm{U} / \mathrm{mL}$ T7 RNA polymerase, $40 \mathrm{mM}$ Tris- $\mathrm{HCl}(\mathrm{pH} 8.1$ at $37^{\circ} \mathrm{C}$ ), $1 \mathrm{mM}$ spermidine, $5 \mathrm{mM}$ dithiothreitol, $0.1 \%$ Triton-X 100, $3.5 \mu \mathrm{g} / \mathrm{mL}$ inorganic pyrophosphatase, and $\mathrm{MgCl}_{2}$ at the concentration determined by the $25 \mu \mathrm{L}$ trial reactions to produce optimal yields of the transcripts. To enhance $\mathrm{HH}$ self-cleavage, $\mathrm{MgCl}_{2}$ was added $2 \mathrm{~h}$ after the start of the transcription so that the final concentration reached $40-48 \mathrm{mM}$ $\mathrm{MgCl}_{2}$; the reaction was continued for an additional $2 \mathrm{~h}$. If necessary, cleavage efficiency was improved by heating the transcription reaction to $95^{\circ} \mathrm{C}$ for $5 \mathrm{~min}$ followed by cooling on ice for $15 \mathrm{~min}$ and incubating the reaction at room temperature overnight. Cleavage efficiency was tested by denaturing PAGE $(20 \%$ acrylamide, $8 \mathrm{M}$ urea) and RNA was visualized with $0.1 \%$ toluidine blue. The reaction was stopped by adding $0.5 \mathrm{M}$ EDTA, pH 8.0 to a final concentration of $50 \mathrm{mM}$.

\section{Purification and desalting}

RNAs were purified using the UltiMate 3000 HPLC system (Thermo Fisher Scientific, Waltham, MA) under denaturing conditions with an anionexchange preparative DNAPac PA100 Nucleic Acid Column (Thermo Fisher Scientific). Purification was performed at $85^{\circ} \mathrm{C}$ at a flow rate of $20 \mathrm{~mL} / \mathrm{min}$. The column was pre-equilibrated with buffer A (urea $6 \mathrm{M}$, Tris/ $\mathrm{HCl} 12.5 \mathrm{mM}, \mathrm{pH}$ 7.4) and pre-heated to $85^{\circ} \mathrm{C}$ (22). After loading the sample onto the column through a $20 \mathrm{~mL}$ sample loop, a $520 \mathrm{~mL}$ gradient of buffer B (urea $6 \mathrm{M}$, Tris/ $\mathrm{HCl}$ $12.5 \mathrm{mM}, 500 \mathrm{mM} \mathrm{NaClO} 4, \mathrm{pH}$ 7.4) up to $50 \%(250 \mathrm{mM} \mathrm{NaClO} 4)$ was performed while collecting $10 \mathrm{~mL}$ fractions. Then the system was adjusted to a steep gradient up to $100 \%$ buffer B to wash off remaining uncleaved RNA and plasmid DNA template (Figure 3). Absorbance was monitored continuously at $260 \mathrm{~nm}$. The RNA fractions were analyzed by denaturing PAGE $(20 \%$ acrylamide, $8 \mathrm{M}$ urea), and RNA was visualized by $0.1 \%$ toluidine blue staining. Fractions with the desired ssRNA oligonucleotides were pooled for subsequent desalting.

The pooled ssRNA oligonucleotides were desalted with the GE ÄKTA prime FPLC system (GE Healthcare, Little Chalfont, Buckinghamshire, UK) using three 5-mL DEAE weak anion-exchange columns in series or a single $20 \mathrm{~mL}$ DEAE column (both GE Healthcare) with buffer $\mathrm{A} 1$ (20 $\mathrm{mM}$ ammonium bicarbonate, $\mathrm{pH}$ 7.5) and buffer $\mathrm{B} 1$ (2.53 $\mathrm{M}$ ammonium bicarbonate, $\mathrm{pH}$ 8), both degassed for $30 \mathrm{~min}$. Before the desalting procedure, the DEAE column was equilibrated with buffer A1. The sample was diluted 2-fold with buffer $\mathrm{A} 1$ and injected into the sample loop. Chromatography was performed at a flow rate of $5 \mathrm{~mL} / \mathrm{min}$. After loading the sample onto the column, a 200 $\mathrm{mL}$ gradient up to $100 \%$ Buffer B1

Figure 2. RNA transcription and hammerhead (HH) cleavage. (A,C) PAGE analysis of trial transcriptions of RNA710 (A) and RNA736 (C) with different $\mathrm{Mg}^{2+}$ concentrations. Full length, uncleaved transcript, cleaved $\mathrm{HH}$, and the desired single-stranded RNA (ssRNA) product are indicated. (B,D) PAGE analysis of large-scale transcription of RNA710 (B) or RNA736 (D). The time after transcription start is indicated. After $6 \mathrm{~h}$ (B) or $4 \mathrm{~h}$ (D), almost all fulllength transcripts are cleaved; * dimeric RNA species. RNA was visualized with $0.1 \%$ toluidine blue. Lane $M$ is an RNA ladder from 26 to 120 nucleotides. 

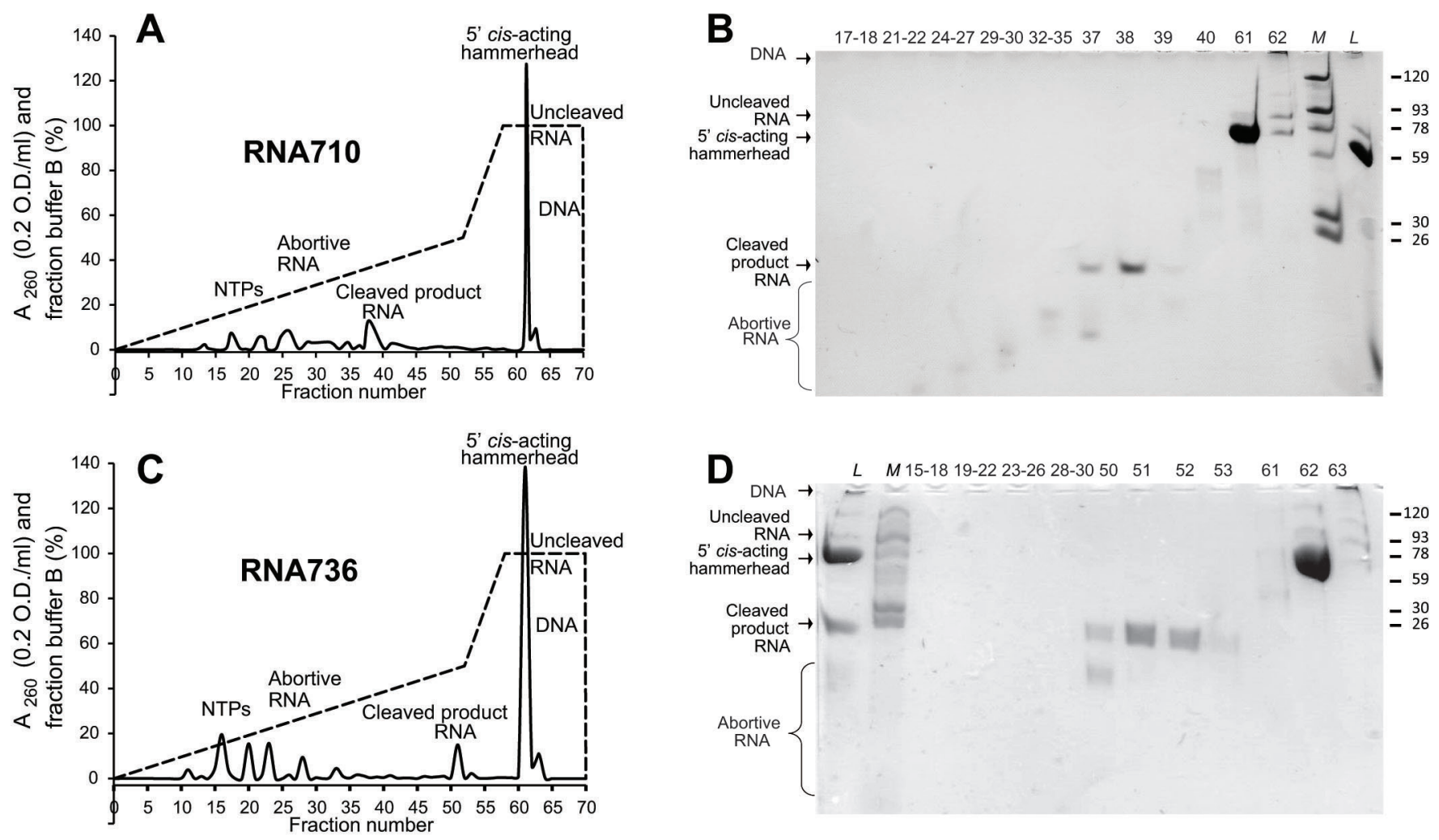

Figure 3. RNA purification using denaturing anion-exchange HPLC. (A,C) Elution profile of RNA710 (A) or RNA736 (C) oligonucleotides purified from the $5 \mathrm{~mL}$ in vitro transcription reaction using a preparative, anion-exchange DNAPac PA100 Nucleic Acid Column. Free rNTPs, small abortive transcripts, as well as cleaved hammerhead $(\mathrm{HH})$, full-length uncleaved transcripts, and DNA template are separated from the desired single-stranded RNA (ssRNA) oligonucleotide. The solid line represents absorbance at $260 \mathrm{~nm}$; the dashed line is the buffer B gradient trace. (B,D) Denaturing PAGE (20\% acrylamide, $8 \mathrm{M}$ urea) analysis of the eluted fractions of RNA710 (B) and RNA736 (D) transcription reaction visualized by staining with $0.1 \%$ toluidine blue. Line $L$ contains a crude transcription reaction, lane $M$ contains an RNA ladder from 26 to 120 nucleotides, and lane $m$ contains a 10 and 12 nucleotides RNA marker. All other lanes are numbered according to fraction numbers corresponding to major peaks from elution profiles from (A) or (C).

was performed while collecting $10 \mathrm{~mL}$ fractions. Absorbance was monitored continuously at $260 \mathrm{~nm}$ (Figure 4). Fractions with the desired RNA product were collected, yields were estimated, and samples were lyophilized. The yield was calculated using Beer-Lambert's law with the equation $A=C^{*}{ }^{\star} E[A$ : absorbance at $260 \mathrm{~nm}$ measured for hydrolyzed ssRNA by a NanoDrop spectrophotometer (Thermo Fisher Scientific, Waltham, MA); c: molar concentration (M); /: path length (in NanoDrop software / for nucleic acids is normalized to $1 \mathrm{~cm}$ ); $E$ : extinction coefficient $\left(\mathrm{M}^{-1} \mathrm{~cm}^{-1}\right)$ calculated for each hydrolyzed ssRNA with the Oligo Extinction Coefficient Calculator from the Williamson group (www.scripps. edu/california/research/dna-proteinresearch/forms/biopolymercalc2. html). After lyophilization, RNAs were dissolved in HPLC-grade Chromasolv water, analyzed by MALDI-TOF mass spectrometry (MS), and stored at $-20^{\circ} \mathrm{C}$ for further experiments.

\section{MALDI-TOF MS analysis}

The samples in a volume of $0.6 \mu \mathrm{L}$ were mixed with $2.4 \mu \mathrm{L}$ the matrix solution $(75 \mathrm{mg} / \mathrm{mL}$ 3-hydroxypicolinic acid in a 1:1 acetonitrile/water mixture, $\mathrm{v} / \mathrm{v}$ ), deposited onto a stainless steel MALDI target, and allowed to dry at room temperature. MALDI-TOF mass spectra were obtained using an Ultraflextreme instrument (Bruker Daltonik, Bremen, Germany) operated in either linear/reflectron or positive/negative ion detection modes (depending on the signal quality).

\section{Isothermal titration calorimetry (ITC)} ITC experiments were performed on a VP-ITC instrument (Microcal, Northampton, MA). The calorimeter was calibrated according to the manufacturer's instructions. Protein samples were prepared as previously described (23). Concentrations of proteins and RNAs were determined using optical absorbance at $280 \mathrm{~nm}$ and $260 \mathrm{~nm}$, respectively. TDP-43 RBD proteins (5 $\mu \mathrm{M})$ were titrated with $50 \mu \mathrm{M}$ RNA602 or AUG12 (Dharmacon GE Healthcare) by 50 injections of $5 \mu \mathrm{L}$ every 3 min at $25^{\circ} \mathrm{C}$. Raw data were integrated, normalized for molar concentration, and analyzed according to a 1:1 RNA:protein ratio binding model. The fits were accomplished using the nonlinear LevenbergMarquardt method with Origin 7.0 software. The values with fitting error are indicated in Supplementary Figure S4.

\section{NMR measurement}

NMR measurements for the TDP-43 RBD-ssRNA complex were performed in NMR buffer (50 mM potassium phosphate, $2.5 \mathrm{mM}$, 2-mercaptoethanol, $\mathrm{pH}$ 6.8) at 298K using Bruker AVIII-700 $\mathrm{MHz}$ and Avance- $950 \mathrm{MHz}$ spectrometers (Bruker Biospin, Rheinstetten, Germany) equipped with cryoprobes. The $2 \mathrm{D}^{1} \mathrm{H}-{ }^{13} \mathrm{C}$ HSQC, ${ }^{1} \mathrm{H}-{ }^{15} \mathrm{~N} H S Q C$, and 3D NOESY ${ }^{1} \mathrm{H}-{ }^{13} \mathrm{C}$ HSQC were acquired on a $756 \mu \mathrm{M}$ 1:1 complex of ${ }^{13} \mathrm{C},{ }^{15} \mathrm{~N}$-labeled UG-rich RNA602 with ${ }^{15} \mathrm{~N}$-labeled TDP-43 RBD (23). Data were processed using Topspin 

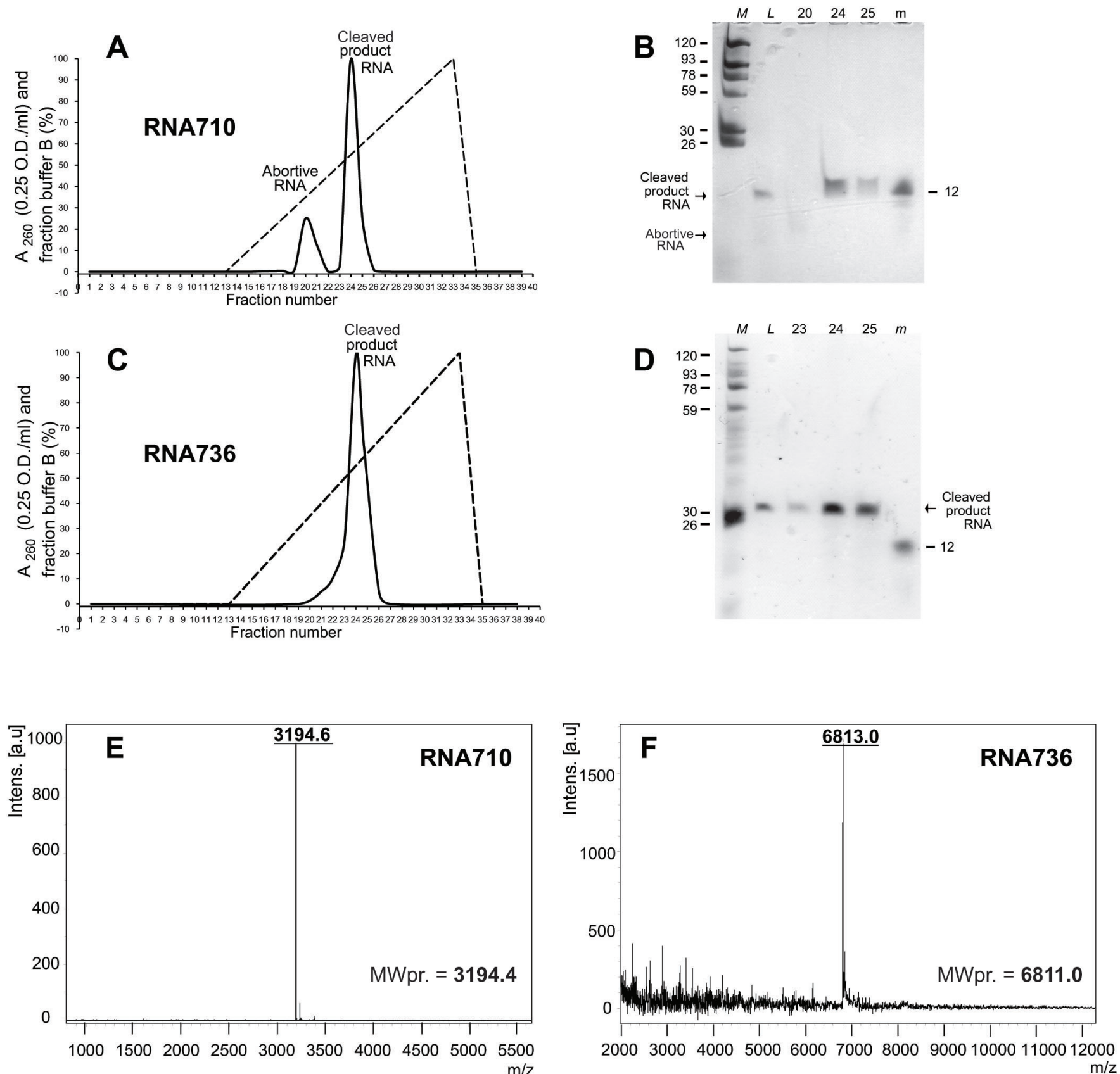

Figure 4. Obtaining desalted single-stranded (ssRNA) oligonucleotides with subsequent MALDI-TOF MS analysis. Elution profiles of RNA710 (A) and RNA736 (C) pooled from purification using denaturing anion-exchange HPLC. Small abortive RNA oligonucleotides can be separated from desired ssRNA product during the desalting step by weak anion-exchange FPLC. (A) The solid line represents absorbance at $260 \mathrm{~nm}$; the dashed line represents the buffer B gradient trace. 20\% PAGE analysis of the fractions eluted during weak anion-exchange chromatography with ammonium bicarbonate buffer for RNA710 (B) or RNA736 (D). Lane $L$ contains pooled fractions after HPLC separation; lane $M$ contains an RNA ladder from 26 to 120 nucleotides; lane m contains a 12 nucleotide RNA. Lanes are numbered according to numbers of fractions indicated in the elution profiles for RNA710 or RNA736. MALDI-TOF mass spectra of the purified RNA710 (E) and RNA736 (F) oligonucleotides; MWpr.: predicted molecular weight. MWpr. for RNA710 corresponds to monoisotopic mass, for RNA736 to average mass.

3.0 (Bruker BioSpin) and analyzed with CARA (http://cara.nmr.ch) or Sparky (www.cgl.ucsf.edu/home/sparky/).

\section{Results and discussion}

Two major problems of in vitro transcription of small ssRNA oligonucleotides (<20 nucleotides) are low transcription yield and heterogeneity at both ends. In order to overcome these problems and obtain homogenous short ssRNA oligonucleotides $(<20$ nucleotides) from in vitro transcription in a cost-effective way, we decided on the following approach. A 5 cis-acting ribozyme with a 5'-GGGAGA-3' starter sequence is used to minimize abortive transcripts and to obtain a clean $5^{\prime}$ end of the ssRNA oligonucleotide with the sequence of choice $(10,24)$. We chose a $5^{\prime}$ cis-acting $\mathrm{HH}$ ribozyme since it is small and yields a very good ssRNA oligonucleotide to ribozyme ratio, it is easy to design and clone, and it has a high cleavage efficiency of up to $95 \%$ during the transcription reaction. The 
5' cis-acting HH RNA oligonucleotide includes the core ribozyme with two stable tetraloops to promote proper folding during transcription as well as the variable helix corresponding to the desired SsRNA oligonucleotide (Figure 1B). Since the stability of the variable helix depends on the length and GC content of the desired ssRNA sequence, melting temperatures usually vary from about $25^{\circ}$ to $40^{\circ} \mathrm{C}$ for $7-12$ base pair helices. Longer helices with higher stability in the variable helix do not increase cleavage efficiency in our hands and thus, depending on the GC content, 8-12 bp helices are optimal for stable $\mathrm{HH}$ formation $\left(\mathrm{Tm}=30^{\circ}-40^{\circ} \mathrm{C}\right)$ with cleavage efficiencies of almost 95\%. Proper folding of the $5^{\prime}$ cis-acting $\mathrm{HH}$ RNA oligonucleotide should be tested using the RNA folding prediction program mfold (25) (Figure 1, C and D). If alternative folds are possible, the variable helix can be modified by replacing $A U$ for $G U$ base pairs or by varying the length. The $3^{\prime}$ end heterogeneity, on the other hand, is reduced by using a plasmid DNA template linearized with BstV2I, which leaves four, singlestranded nucleotides at the $3^{\prime}$ end of the template, thereby increasing the tendency of $\mathrm{T} 7$ polymerase to fall off the template without adding non-templated nucleotides $(10,26)$.

In summary, the most effective transcription of small ssRNA oligonucleotides with minimum small abortive transcripts can be achieved using the following plasmid DNA template sequence: T7 promoter sequence followed by 5'-GGGAGA-3', the variable base paired helix, the $\mathrm{HH}$ core followed by the desired ssRNA sequence, and the BstV2I restriction site flanked by a $5^{\prime}$ Hind III and a $3^{\prime}$ EcoRI site for subcloning into a high copy DNA vector (Figure 1E). The two extra nucleotides that were added right after the desired RNA sequence are necessary for proper digestion of the plasmid by Bst $\mathrm{V} 2 \mathrm{l}$ or its isoschizomers. These restriction enzymes cut two nucleotides downstream from the recognition site on the $5^{\prime}$ end of the antisense strand and six nucleotides from the $3^{\prime}$ end of the sense strand of the DNA template, forming the sticky ends necessary for run-off transcription. All steps from the design of the RNA transcription template to the final product are outlined in Figure 1A and described in the following sections. Usage of linearized plasmid DNA as a template for in vitro RNA transcription not only decreases $3^{\prime}$ end heterogeneity, but also facilitates size- and charge-dependent separation of the DNA template from the ssRNA product $(18,27)$. Since large-scale in vitro transcription reactions require milligram amounts of the DNA template, a high copy number vector such as pUC18 should be used (18). The template insert is prepared by standard PCR techniques, and after insertion and sequencing, the final plasmid is then transformed into $\mathrm{DH} 5 \alpha$ cells to prepare the plasmid DNA.

The plasmid can be quickly purified using the QIAGEN Mega kit with some modifications (detailed in the "Materials and methods" section). Using the QIAGEN-tip Mega 2500 instead of Giga

Table 1. Overview of single-stranded (ssRNA) oligonucleotides prepared by the presented method.

\begin{tabular}{|c|c|c|c|c|}
\hline ssRNA name & $\begin{array}{c}\text { RNA sequence } \\
\left(5^{\prime}-3^{\prime}\right)\end{array}$ & $\begin{array}{c}\text { Yield } \\
(\mathrm{nmol} / \mathrm{mL})\end{array}$ & $\begin{array}{c}\text { Predicted MW } \\
(\mathrm{g} / \mathrm{mol})\end{array}$ & $\begin{array}{c}\text { Measured MW } \\
(\mathrm{g} / \mathrm{mol})\end{array}$ \\
\hline RNA602CN & GUGUGAAUGAAU & 41.7 & 4024.3 & 4021.9 \\
\hline RNA602N & GUGUGAAUGAAU & 48.3 & 3908.3 & 3908.9 \\
\hline RNA602 & GUGUGAAUGAAU & 38.5 & 3859.6 & 3859.7 \\
\hline $\begin{array}{l}\text { RNA602 } \\
15 \% C\end{array}$ & GUGUGAAUGAAU & 32.1 & 3877.7 & 3877.4 \\
\hline RNA695 & GUGUGUGUGUGU & 76.5 & 3845.5 & 3845.5 \\
\hline RNA710 & GUGUGUGUGU & 87.7 & 3194.4 & 3194.6 \\
\hline RNA587N & AAGAGAGA & 34.2 & 2659.7 & 2656.8 \\
\hline RNA675 & AAGAGAGAu & 18.8 & 2923.5 & 2945.6 \\
\hline RNA676 & AAGAGAGACC & 29.1 & 3227.5 & 3227.5 \\
\hline RNA736 & GUGUGAAUGUGUGUGUGAAUG & 26.0 & 6811.0 & 6813.0 \\
\hline
\end{tabular}

$\mathrm{CN}:{ }^{13} \mathrm{C},{ }^{15} \mathrm{~N}$-labeled RNA. N: ${ }^{15} \mathrm{~N}$-labeled RNA; 15\%C: $15 \%{ }^{13} \mathrm{C}$-labeled RNA. Yield indicated per 1 $\mathrm{mL}$ of transcription reaction. Predicted molecular weight (MW) corresponds to average masses, except for RNA675 (monoisotopic mass). Predicted MW of isotope-labeled RNA oligonucleotides is based on $>99 \%$ isotope enrichment. For the RNA675 MALDI-TOF, measurement indicates stable sodium adduct $[\mathrm{M}-2 \mathrm{H}+\mathrm{Na}]^{-}=2945.5$ (monoisotopic mass). 
10000 halves the cost of the final product since it is sufficient for purification of up to $6 \mathrm{mg}$ of plasmid DNA, which is more than double the specified plasmid load recommended by the manufacturer. It is important to obtain strictly RNasefree plasmid DNA in order to prevent rapid decay of ssRNA oligonucleotides during transcription, since even a trace of RNase very efficiently cleaves small ssRNAs. This can be achieved by using more washes of the QIAGENtip Mega 2500 than recommended by the manufacturer. Subsequent regeneration of the tips (as described in the "Materials and methods" section) allows researchers to use the columns multiple times (Supplementary Figure S2A), which considerably reduces the cost. After linearization with BstV2I and confirmation that the plasmid is RNA-free (Supplementary Figure S2), it can be used without any additional purification steps in an in vitro transcription reaction.

The yield of an in vitro transcription reaction depends on the $\mathrm{MgCl}_{2}$ concentration. For every new plasmid DNA template solution, the $\mathrm{Mg}^{2+}$ concentration should be optimized based on small-scale, $25 \mu \mathrm{L}$ trial transcriptions with $\mathrm{MgCl}_{2}$ concentrations varying between 8-48 mM $(18,27)$. As a rule, the best yield is approached at 20-25 mM $\mathrm{MgCl}_{2}$ concentration, but the optimum concentration for RNA transcription is usually not the same as for 5 ' cis-acting $\mathrm{HH}$ ribozyme self-cleavage. For RNA710 or RNA736 (Table 1), the optimum Mg $^{2+}$ concentration for maximum RNA yield is $24 \mathrm{mM}$, while $\mathrm{HH}$ cleavage is most efficient at $48 \mathrm{mM}$ (Figure 2, A and C). Thus, for the best yield of the desired ssRNA product, it is essential to start the transcription reaction with an initially lower $\mathrm{Mg}^{2+}$ concentration for optimum transcription yield and to increase the $\mathrm{Mg}^{2+}$ concentration after 2 hours to reach the optimum for the $\mathrm{HH}$ self-cleavage. If the $\mathrm{HH}$ ribozyme folds properly, selfcleavage efficiency reaches over 95\% (Figure 2, B and D). Once the optimum $\mathrm{Mg}^{2+}$ concentration is determined, transcription reactions can be scaled up. Since sufficient amounts of all enzymes participating in the transcription reaction are essential for the preparation of large quantities of RNA, which could become expensive if commercial enzymes are used, both T7 RNA polymerase and inorganic pyrophosphatase, which prevents $\mathrm{Mg}^{2+}$ depletion during transcription, are prepared in house $(11,20)$. This also helps reduce the cost large-scale production of small ssRNA oligonucleotides.

As the next step, RNA purification from the transcription reaction, which contains proteins and nucleic acids, should be performed. The most commonly used method for purifying large quantities of small RNA oligonucleotides with high resolution is preparative PAGE. Under denaturing conditions, this method allows separation of RNA oligonucleotides up to 70 nucleotides long with single-nucleotide resolution $(9,28)$, but such a technique is quite tedious and takes 6-10 $\mathrm{h}$ followed by lengthy elution of the RNA from the polyacrylamide gel (28). On the other hand, sufficient resolution for small ssRNA oligonucleotides can be achieved with anion-exchange chromatography under denaturing conditions (14). Using a gradient of sodium perchlorate with $6 \mathrm{M}$ urea at high temperature $\left(85^{\circ} \mathrm{C}\right)$ (22), it is possible to separate desired RNA oligonucleotides in the range of 7 to 21 nucleotides from other reaction components within $1 \mathrm{~h}$. We use a gradient of $0 \%-50 \%$ buffer B over 25 min. The desired ssRNA product elutes depending on its size, from $31 \%$ buffer $B$ (155 $\mathrm{mM} \mathrm{NaClO}_{4}$ ) for 7 nucleotides RNA to $50 \%$ buffer B (250 $\left.\mathrm{mM} \mathrm{NaClO}_{4}\right)$ for longer ssRNA oligonucleotides (Figure 3, A and C). For even longer oligonucleotides, the gradient can be tuned to get better separation. Fractions with the desired SSRNA oligonucleotide are confirmed by PAGE analysis (Figure 3, $B$ and D) and then subjected to further purification by desalting.

Buffer exchange through multiple dialysis steps of the desired ssRNA oligonucleotides to remove urea and salts for further studies usually takes at least $12 \mathrm{~h}$ (18), and some remnants of salt, especially sodium, which can complicate MS analysis, can still be found in the solution after multiple buffer exchanges through dialysis. As a quick alternative method of buffer exchange and desalting, we used weak anionexchange chromatography with an FPLC system using volatile buffers. With this method, we obtained salt-free ssRNA oligonucleotides that are perfectly compatible with further MS analysis and other biochemical and biophysical studies. For the desalting procedure, the pooled fractions from HPLC containing the desired RNA oligonucleotides are loaded onto a DEAE (diethylaminoethanol) column equilibrated with $20 \mathrm{mM}$ ammonium bicarbonate solution and then a gradient of $2.53 \mathrm{M}$ ammonium bicarbonate concentration is applied at high flow rates $(5 \mathrm{~mL} / \mathrm{min})$. The desired ssRNA oligonucleotides usually elute at 1-1.5 M ammonium bicarbonate (Figure 4). This buffer exchange procedure takes only 1 hour. An additional benefit of this desalting method is that it also separates RNA oligonucleotides based on charge but this time under native conditions. Thus, it is possible to further purify the desired ssRNA product from shorter RNA oligonucleotides in case the HPLC separation did not yield entirely pure fractions of the desired SsRNA oligonucleotide (Figure 4, A and B). Fractions with the desired RNA product, confirmed by PAGE analysis, are then lyophilized overnight. Thus, after two sequential purification steps without any intermediate procedures, one obtains pure ssRNA oligonucleotides ready for further studies. The mass and purity of RNA oligonucleotides was confirmed by MALDI-TOF MS (Figure 4, E and F, Table 1, Supplementary Figures S3 and S6).

To further assess the quality of the ssRNAs, we compared ITC measurements of TDP-43 RBD with RNA602 and a commercial ssRNA oligonucleotide (AUG12) with the same sequence (23). Virtually identical data were obtained for both ssRNA oligonucleotides with $K_{d}$ values in the low nanomolar range (Supplementary Figure S4). In addition, we used RNA602 oligonucleotide with different labeling schemes (Table 1) for the structure determination of its complex with TDP-43 RBD (23). To date, only four ssRNAprotein complexes employing isotopelabeling of the RNA have been published (23,29-31). Three complex structures used SSRNA oligonucleotides synthesized with phosphoramidites containing ${ }^{13} \mathrm{C}$-labeled ribose moieties that are not commercially available (32). The TDP-43 RBD complex with UG-rich RNA602 used isotope-labeled ssRNA oligonucleotides prepared by our method. The ${ }^{15} \mathrm{~N}$-isotope labeling of the 
RNA602 oligonucleotide allowed us to unambiguously distinguish hydrogenbonded guanosine from uracil imino protons, and the ${ }^{13} \mathrm{C}$-isotope labeling was essential for the assignment of intra- and intermolecular ssRNA ribose contacts (Supplementary Figure S5). We believe that future biochemical and biophysical studies of ssRNA-protein complexes, including structure determination by NMR spectroscopy, will similarly benefit from our robust protocol for preparation and purification of short ssRNA oligonucleotides.

\section{Author contributions}

P.J.L. designed the study. P.J.L., M.Z., M.-Y.C., and L.S. performed the experiments. O.S. provided the MS analysis. P.J.L. and M.Z. wrote and edited the manuscript. All authors contributed to the revision of the manuscript.

\section{Acknowledgments}

We thank all members of the RNA-based Regulation of Gene Expression and the Protein-DNA Interactions groups at CEITEC for very useful advice. We thank the members of the Josef Dadok National NMR Centre for maintenance of the NMR instruments. The work was done with support of the Proteomics Core Facility of CEITEC. This work was supported by the projects "CEITEC - Central European Institute of Technology" (CZ.1.05/1.1.00/02.0068) from the European Regional Development Fund, by the EU Seventh Framework Programme under the "Capacities" specific programme (Contract No. 286154 - SYLICA) and INBIOR (CZ.1.07/2.3.00/20.0042); by funding to P.J.L. from a Marie Curie Action - Career Integration Grant (PCIG14-GA2013-630758), an EMBO Installation Grant (3014), a Czech Science Foundation Grant (P305/15/21122S), and a Human Frontier Science Program Grant (RGP0024/2008); by funding to O.S. from a Czech Science Foundation project GBP206/12/G151.

\section{Competing interests}

The authors declare no competing interests.

\section{References}

1. Moore, M.J. and N.J. Proudfoot. 2009. Pre-mRNA processing reaches back to transcription and ahead to translation. Cell 136:688-700.
2. Kornblihtt, A.R., I.E. Schor, M. Alló, G. Dujardin, E. Petrillo, and M.J. Muñoz. 2013. Alternative splicing: a pivotal step between eukaryotic transcription and translation. Nat. Rev. Mol. Cell Biol. 14:153-165.

3. Wahl, M.C., C.L. Will, and R. Lührmann. 2009. The spliceosome: design principles of a dynamic RNP machine. Cell 136:701-718.

4. Jackson, R.J., C.U.T. Hellen, and T.V. Pestova. 2012. Termination and post-termination events in eukaryotic translation. Adv Protein Chem Struct Biol. 86:45-93.

5. Martin, K.C. and A. Ephrussi. 2009. mRNA localization: gene expression in the spatial dimension. Cell 136:719-730.

6. Maquat, L.E. and C. Gong. 2009. Gene expression networks: competing mRNA decay pathways in mammalian cells. Biochem. Soc. Trans. 37:1287-1292.

7. Milligan, J.F. and O.C. Uhlenbeck. 1989. Synthesis of small RNAs using T7 RNA polymerase. Methods Enzymol. 180:51-62.

8. Pokrovskaya, I.D. and V.V. Gurevich. 1994. In vitro transcription: preparative RNA yields in analytical scale reactions. Anal. Biochem. 220:420-423.

9. Batey, R.T. 2014. Advances in methods for native expression and purification of RNA for structural studies. Curr. Opin. Struct. Biol. 26:1-8.

10. Price, S.R., N. Ito, C. Oubridge, J.M. Avis, and K. Nagai. 1995. Crystallization of RNAprotein complexes I. Methods for the large-scale preparation of RNA suitable for crystallographic studies. J. Mol. Biol. 249:398-408.

11. Koubek, J., K.F. Lin, Y.R. Chen, R.P. Cheng, and J.J.T. Huang. 2013. Strong anionexchange fast performance liquid chromatography as a versatile tool for preparation and purification of RNA produced by in vitro transcription. RNA 19:1449-1459.

12. Martins, R., J.A. Queiroz, and F. Sousa. 2014. Ribonucleic acid purification. J. Chromatogr. A 1355:1-14.

13. Lu, C. and P. Li. 2012. Preparation of short RNA by in vitro transcription. Methods Mol. Biol. 941:59-68.

14. Shields, T.P., E. Mollova, L. Ste Marie, M.R. Hansen, and A. Pardi. 1999. High-performance liquid chromatography purification of homogenous-length RNA produced by trans cleavage with a hammerhead ribozyme. RNA 5:1259-1267.

15. Wang, X., C. Li, X. Gao, J. Wang, and X. Liang. 2015. Preparation of Small RNAs Using Rolling Circle Transcription and Site-Specific RNA Disconnection. Mol Ther Nucleic Acids. 4:e215.

16. Latham, M.P., D.J. Brown, S.A. McCallum, and A. Pardi. 2005. NMR methods for studying the structure and dynamics of RNA. ChemBioChem 6:1492-1505.

17. Eichhorn, C.D. and H.M. Al-Hashimi. 2014. Structural dynamics of a single-stranded RNA-helix junction using NMR. RNA 20:782791.

18. Lukavsky, P.J. and J.D. Puglisi. 2004. Large-scale preparation and purification of polyacrylamide-free RNA oligonucleotides. RNA 10:889-893.

19. Siddappa, N.B., A. Avinash, M. Venkatramanan, and U. Ranga. 2007. Regeneration of commercial nucleic acid extraction columns without the risk of carryover contamination. Biotechniques 42:186-192.

20. Grodberg, J. and J.J. Dunn. 1988. ompT encodes the Escherichia coli outer membrane protease that cleaves T7 RNA polymerase during purification. J. Bacteriol. 170:1245-1253.

21. Easton, L.E., Y. Shibata, and P.J. Lukavsky. 2010. Rapid, nondenaturing RNA purification using weak anion-exchange fast performance liquid chromatography. RNA 16:647-653.

22. Duss, O., C. Maris, C. von Schroetter, and F.H.-T. Allain. 2010. A fast, efficient and sequence-independent method for flexible multiple segmental isotope labeling of RNA using ribozyme and RNase $\mathrm{H}$ cleavage. Nucleic Acids Res. 38:e188.

23. Lukavsky, P.J., D. Daujotyte, J.R. Tollervey, J. Ule, C. Stuani, E. Buratti, F.E. Baralle, F.F. Damberger, and F.H.-T. Allain. 2013. Molecular basis of UG-rich RNA recognition by the human splicing factor TDP-43. Nat. Struct. Mol. Biol. 20:1443-1449.

24. Meyer, M. and B. Masquida. 2014. cis-Acting 5 ' hammerhead ribozyme optimization for in vitro transcription of highly structured RNAs. Methods Mol. Biol. 1086:21-40.

25. Zuker, M. 2003. Mfold web server for nucleic acid folding and hybridization prediction. Nucleic Acids Res. 31:3406-3415.

26. Walker, S.C. 2003. General plasmids for producing RNA in vitro transcripts with homogeneous ends. Nucleic Acids Res. 31:e82.

27. McKenna, S.A., I. Kim, E.V. Puglisi, D.A. Lindhout, C.E. Aitken, R.A. Marshall, and J.D. Puglisi. 2007. Purification and characterization of transcribed RNAs using gel filtration chromatography. Nat. Protoc. 2:3270-3277.

28. Petrov, A., T. Wu, E.V. Puglisi, and J.D. Puglisi. 2013. RNA purification by preparative polyacrylamide gel electrophoresis. Methods Enzymol. 530:315-330.

29. Hargous, Y., G.M. Hautbergue, A.M. Tintaru, L. Skrisovska, A.P. Golovanov, J. Stevenin, L.-Y. Lian, S.A. Wilson, and F.H.-T. Allain. 2006. Molecular basis of RNA recognition and TAP binding by the SR proteins SRp20 and 9 G8. EMBO J. 25:5126-5137.

30. Auweter, S.D., R. Fasan, L. Reymond, J.G. Underwood, D.L. Black, S. Pitsch, and F.H.-T. Allain. 2006. Molecular basis of RNA recognition by the human alternative splicing factor Fox-1. EMBO J. 25:163-173.

31. Oberstrass, F.C., S.D. Auweter, M. Erat, Y. Hargous, A. Henning, P. Wenter, L. Reymond, B. Amir-Ahmady, et al. 2005. Structure of PTB bound to RNA: specific binding and implications for splicing regulation. Science 309:2054-2057.

32. Wenter, P., L. Reymond, S.D. Auweter, F.H.-T. Allain, and S. Pitsch. 2006. Short, synthetic and selectively 13C-labeled RNA sequences for the NMR structure determination of protein-RNA complexes. Nucleic Acids Res. 34:e79.

Received 05 September 2015; accepted 12 December 2015.

Address correspondence to Peter J. Lukavsky. Central European Institute of Technology, Masaryk University, Brno, 62500, Czech Republic. E-mail: peter.lukavsky@ceitec.muni.cz

To purchase reprints of this article, contact: biotechniques@fosterprinting.com 